\title{
OPTIMAL MILK DISPOSAL EQUIPMENT DESIGN IN BOTTLE WITH ERGONOMICS APPROACH
}

\author{
Mujiono $^{1 *}$, Sujianto ${ }^{1}$, Addy Utomo ${ }^{2}$ \\ ${ }^{1}$ Industrial Engineering, National Institute of Technology (ITN) Malang, Indonesia \\ ${ }^{2}$ Electrical Engineering, National Institute of Technology (ITN) Malang, Indonesia
}

*Corresponding Email: mujiono1064@ gmail.com

\begin{abstract}
The results of the observation conducted by the research team at the milk processing company in the waste, the phase of waste destruction through the stage of one of them is the disposal of milk from the bottle is still using the manual tool when the bottle hole and pour the milk fluid into the tub. The milk disposal time in the bottle can be optimised with ergonomic tool design process. The meaning of ergonomic design is the design of a tool that generates a working system using the size of Anthropometri, while the research is focused on ergonomic tool design that can be used by the operator with the effective efficient, safe and comfortable result.

With the stage conducted by the research team was conducting surveys, study of literture, data collection, formulating problems, analyzing and outdoor that is targeted is optimal model design tool using size anthropometri with height of shoulders when standing along the $138.5 \mathrm{~cm}$, reach of the fore hands $72 \mathrm{~cm}$, the range of the side hand of $71 \mathrm{~cm}$, the height of the elbow when standing $104 \mathrm{~cm}$ and the knee height when standing $49 \mathrm{~cm}$ by saving the discharge time by $37 \%$.
\end{abstract}

Keywords: tool design, productivity, ergonomi

\section{Introduction}

The location of this research is done in indomilk liquid milk processing Company (SCI). Where the production process includes Formulating processes \& Dumping, Mixing, HomoPast, SV, Unscreamble, Filler, Loader, Sterilizer, Unloader, Labeller, CasePacker and the last Palletizer.

This research is done in one part of sewage disposal, where for the destruction of waste process includes the stage of one of the milk productions in the bottle. The workers in the disposal part carry out their works in manual way that is when the bottle hole and pour milk fluid into the place with a stoop position and the seat has no backup so that the operator easily gets fatigue.

The problem faced by the waste milk processing industry is: How to design an ergonomic disposal device with the aim: designing ergonomic disposal work, so that the operator could work on the process safely and comfortably.

\section{Basic Theory}

\subsection{Designing}

Design functions become more important in defining the physical shape of the product to meet customer needs. In this case the task of the design section includes engineering design (mechanical, electrical, software, etc.) and industrial design, aesthetics, ergonomics, user interface [1, 2].

Aspets that effect work facility of work facilities can be influnced by several aspects that come from various disclipines (specilizations) of existing expertise.

The second aspect to be cosidered is the need for data relating to the dimensions of human body (anthropometric data) this anthropometric data will support product design process with the aim of finding a harmonious relationship between the product and the people who use it [2]. 


\subsection{Ergonomics}

The meaning of ergonomic design is the design of a tool that generates a working system using the size of Anthropometri. In designing an ergonomic work system, there are five planning principles to consider $[1,3]$ :

a. Make the machine adapted to the operator.

b. Minimizes percentage of beyond design.

c. Work plan to be more balanced.

d. Emphasize the importance of comunication.

e. Use the machine in enlarging human abilities.

The main conclusions regarding the discipline of ergonomics, as follow [4]:

1. Closely related to the human aspect ini planning "man-made objects" and researching the capabilities of human limitation, both physically and mentally, psychologically and interactions in an integral human machine system.

2. Ergonomics is defined as "a disclipline concerned with designing man-made objects (equipment) so that people can use them effectively and savely and creating environments suitable for human living and work".

3. The main objective of ergonomics discipline approach is directed at the efforts to improve human work performance such as increasing work speed, accuracy, and work safe.

4. The special approach that exist $s$ in the ergonomics discipline is the systematic application of all relevant information relating to human behavior and in the design of equipment, facilities and work environment.

\subsection{Anthropometri}

Anthropometry can be interpreted as a science that specifically learns matters relating to the measurement of the human body, which is used to determine differences (traits or characteristics) in individuals, groups and the others [5]. With regard to the measurement of certain forms and characteristics of the human body, anthropometry can also be interpreted as a science that is specifically related to the investigation of the human body used to determine differences in individuals and groups. This measurement is certainly in accordance with the planning of work tools. Anthropometri used for the design include: height of the shoulder when standing, reach of the fore hands, the reach of the hands of the side, the height of the eyes when standing, the height of the standing elbow, high navel when standing, the height of the knee when standing, and the width of the index finger.

The anthropometric data used for the design of this tool are follows [6]:

\section{Elbow to Height}

The distance measured vertically from the floor surface to the lowest part of the lowest part of the elbow where the upper and lower arms meet, as shown in Figure 1.

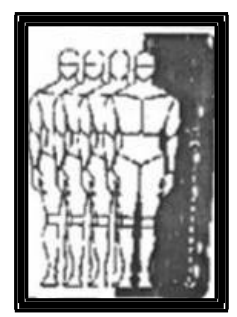

Figure 1 Elbow to Height

\section{Side Arm Reach}

The distance from the center line of Standart time line of the body to the outer surface of bar grasped with the right hand, while the subjects is in an upright position with the arms stretched horizontal without causing discomfort or pain, as shwon in Figure 2.

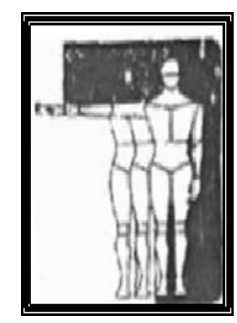

Figure 2 Side Arm Reach

\section{Thumb Tip Reach}

The distance from the wall to the tip of the thumb as measured by the position of the shoulder against the wall, the arm stretched forward and subject index finger touching the tip of the thumb, as shown in Figure 3.

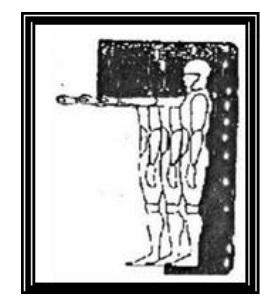

Figure 3 Thumb Tip Reach 


\section{Standart Time}

Standard time can be obtained by adding looseness or

Allowance at normal time, mathematically as follows [7, 8]:

$W_{b}=W_{n} \times \frac{100 \%}{100 \%-\text { allownce }(\%)}$

Standard Output

$$
O_{s}=\frac{1}{W_{b}}
$$

Where:

$O_{s}=$ Standard Output

$W_{b}=$ Standart Time

$W_{n}=$ Normal Time

\section{Research Methods}

The research method that is done is to collect the data from the operator anthropometri that will be used to do such as: height of the shoulder when standing is used to determine the height of the appliance, the reach of the fore hands used to determine the width of the appliance, the range of the hand of the Before using the tool obtained data per carton with a flat is [6]:

Opening carton (3.7 seconds) $=>$ Mencoblos Bottle $(7.24 \mathrm{sec})=>$ To transfer Milk fluid $(7.88 \mathrm{sec})=>$ to transfer the empty bottle into the basket $(7,7 \mathrm{sec})=>$ Carton Folding $(4,3 \mathrm{sec})$ $=>$ Smoothed Carton $(8.4 \mathrm{sec})=>$ inserting bottle into plastic bag $(6,3 \mathrm{sec})=>$ Tidy up Plastic bag $(4.1 \mathrm{sec})$ with total amount of time required: 49.6 seconds

Using a new means of working for milk disposal by:

Opening cartons ( 3 seconds) using the tool (30 seconds)) with the total amount of time required: 31 seconds.

\section{Research and Discussion Results}

\subsection{Research Results}

The anthropometric measurements used to design this work facility are : shoulder height when standing with $5 \%$ of $138,5 \mathrm{~cm}$ is used to determine the height of the tool, forward hand reach with $50 \%$ of $71 \mathrm{~cm}$ for tool length, elbow height when standing with $5 \%$ of $104 \mathrm{~cm}$ for on button height, and knee height when standing with $5 \%$ of $49 \mathrm{~cm}$ used to determine the output funnel height. Used for the design of work facilities as shown in Figure 4.

Data calculation result of Anthropometri as shown in the Table 1.

Table 1 Calculation result Anthropometri

\begin{tabular}{|c|c|c|c|}
\hline Type of Data & \multicolumn{3}{|c|}{ Percentile in $\mathrm{cm}$} \\
\hline & $5 \%$ & $50 \%$ & $95 \%$ \\
\hline $\begin{array}{ll}\text { High } & \text { shoulder } \\
\text { standing } & \end{array}$ & 138.5 & & \\
\hline Reach Fore Hands & & 72 & \\
\hline $\begin{array}{l}\text { Range of Sideways } \\
\text { hands }\end{array}$ & & 71 & \\
\hline $\begin{array}{l}\text { High elbow when } \\
\text { standing }\end{array}$ & 104 & & \\
\hline High knee standing & & 49 & \\
\hline
\end{tabular}

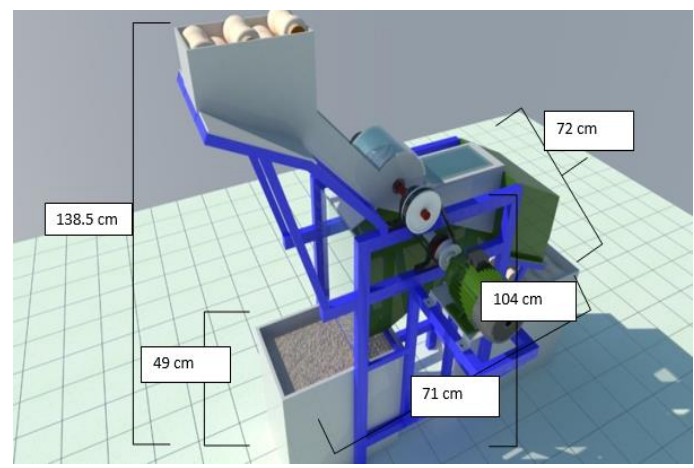

Figure 4 Design Result

Disposal time using manual obtained data [9]:

Cycle time $(\mathrm{Ws})=0.83$ minutes

Performance $(\mathrm{P})=1.11$

Allowance $\%=29 \%$

Retrieved Norman (Wn)

$W_{n}=W_{s} \times P=0.83 \times 1.1$.

$W_{n}=0.92 \mathrm{~min}$ utes / carton

$W_{b}=W_{n} \times \frac{100 \%}{100 \%-\text { allownce }(\%)}$

$W_{b}=0.92 \times \frac{100 \%}{100 \%-29}=1.29$ min utes / carton 
$O_{s}=\frac{1}{W_{b}}=\frac{1}{1.29}=0.77$ carton $/$ menutes

$O_{s}=46.2$ carton / hour

Disposal time using new means of employment

Cycle time $(\mathrm{Ws})=0.52$ minutes

Performance $(\mathrm{P})=1.11$

Allowance \% $=29 \%$

Retrieved Norman (Wn)

$W_{n}=W_{s} \times P=0.52 \times 1.1$.

$W_{n}=0.58 \mathrm{~min}$ ute /

hour

$W_{b}=W_{n} \times \frac{100 \%}{100 \%-\text { allownce }(\%)}$

$W_{b}=0.58 \times \frac{100 \%}{100 \%-29}=0.82 \mathrm{~min}$ ute / carton

$O_{s}=\frac{1}{W_{b}}=\frac{1}{0.82}=1.22$ carton / min ute

$O_{s}=73.2$ carton / hour

\subsection{Analizing Data}

\section{Tools Specifications}

$\begin{array}{ll}\text { Machine Type } & : \text { YUEMA SA B35 } \\ \text { Capacity } & : \text { 70-75 dos/hour } \\ \text { Dimensions } & : 72 \mathrm{~cm} 71 \mathrm{cmx} 138.5 \mathrm{~cm} \\ \text { Power Motor Electric } & : 1 \mathrm{HP}(1500 \mathrm{rpm}) \\ \text { Machine Weight (tool) } & : \pm 30 \mathrm{Kg} \\ \text { Cut Result } & : \text { Split two } \\ \text { Knife } & : \text { Stainless } \\ \text { Order } & : \text { Steel } 5 \text { x } 5 \text { thick } 4 \\ \text { mm } & : \text { MS Plate, } \\ \text { Cylinder } & : 50 \mathrm{~cm}, \\ \text { Diameter } & : 4 \mathrm{~mm} \\ \text { Thickness } & : \text { Rotate } \\ \text { Cup side cylinder : thick } \text { MS Plate: } 1.5 \mathrm{~mm} \\ \text { Knife System } & : 1 \mathrm{PCs} \\ \text { Number of knives } & \end{array}$

The result shows that standard output of 46.2 cartons/hour was with a new facility obtained 73.2 cartons/hour to be gained productivity by $37 \%$.

\section{Conclusion}

The work facilities to know the time of the milk disposal in the bottle can be optimised with ergonomic tool design process. The ergonomic design in this case is the design of a tool that generates a working system using the anthropometri size [3].

Size Anthropometri used is: the height of the shoulder when standing with a percentage of $5 \% 138.5 \mathrm{~cm}$, the fore-hands with a percentile $50 \%$ by $72 \mathrm{~cm}$, the reach of a lateral hand with a percentile $50 \%$ at $7 \mathrm{~cm}$, the elbow height is $5 \%$ percentile of $104 \mathrm{~cm}$, and the knee height stands with a $5 \%$ percentile of $49 \mathrm{~cm}$. While the results of the analysis obtained the standard output of 46.2 cardboard/hour, medium with a new means obtained 73.2 cardboard/hour so that it was obtained productivity by $37 \%$.

\section{References}

[1] Das B, Sengupta a. k. 2016. Industrial Workstation Design: A. Systematic ergonomics approach, Applied Ergonomics, Vol 27, No. 3,157-163. http://dx.doi.org/10.1016/003-6870 (96) 00008-7

[2] Wigjosoebroto, Sritomo. 2003. Ergonomics, motion and time Studies, the first edition of the second mold.

[3] Yaar H, Bechar A, Riemer R, Raschke S. 2017. Automated Simulation-Based Workplace design that conseders ergonomics and Productivity, International journal Simulation Design (1) 5-18,1726-4529.

http://dx.doi.org/10.2507/IJSIMM16 (1) 1.355

[4] Del Rio Vilas. D, Longo F, Monteil N. R 2013. A General themanufacturing workstation design optimization: A. Combined ergonomics and operational approach, simulation, Vol. 89, No. 3, 306-329.

http://dx.doi.org/10.1177/00375497124 62862

[5] Mujiono. 2019. The design of the elephant grass swimware with the ergonomics rules. Journal of Innovative Industry, ITN Malang.

[6] Mujiono, 2013, design of ergonomic cardboard box maker based on anthopometric size, Vol. 3, No. 2, Innovative journal ITN Malang. 
[7] Mujiono, 2016, improvement of work facilities for corn thresher with ergonomics rules, Vol 6, No. 2, innovative journals, ITN Malang.

[8] Nurmianto, Eko. Ergonomics of motion and Time studies, 2014 ITS for Widya Surabaya.

[9] J. Supranto. 2001. Theory and Application statistics, Sixth edition. Brian, London. 